\title{
The respiratory control of carbon dioxide in children and adolescents referred for treatment of psychogenic non-epileptic seizures
}

\author{
Kasia Kozlowska ${ }^{1,2,3}$ (D) Reena Rampersad $^{1,3} \cdot$ Catherine Cruz $^{1} \cdot$ Ubaid Shah $^{1,3,4}$. \\ Catherine Chudleigh $^{1,3} \cdot$ Samantha Soe $^{1,3} \cdot$ Deepak Gill $^{1,3} \cdot$ Stephen Scher ${ }^{3,5,6}$. \\ Pascal Carrive ${ }^{7}$
}

Received: 12 January 2017 / Accepted: 6 March 2017 / Published online: 24 March 2017

(C) The Author(s) 2017. This article is an open access publication

\begin{abstract}
Psychogenic non-epileptic seizures (PNES) are a common problem in paediatric neurology and psychiatry that can best be understood as atypical responses to threat. Threats activate the body for action by mediating increases in arousal, respiration, and motor readiness. In previous studies, a range of cardiac, endocrine, brain-based, attention-bias, and behavioral measures have been used to demonstrate increases in arousal, vigilance, and motor readiness in patients with PNES. The current study uses respiratory measures to assess both the motor readiness of the respiratory system and the respiratory regulation of $\mathrm{CO}_{2}$. Baseline respiratory rates during clinical assessment and arterial $\mathrm{CO}_{2}$ levels during the hyperventilation component of routine video electroencephalogram were documented in 60
\end{abstract}

Electronic supplementary material The online version of this article (doi:10.1007/s00787-017-0976-0) contains supplementary material, which is available to authorized users.

Kasia Kozlowska

Kkoz6421@uni.sydney.edu.au; Kasiak@health.gov.nsw.au

Reena Rampersad

Reena.rampersad@health.nsw.gov.au

Catherine Cruz

Catherine.cruz@health.nsw.gov.au

Ubaid Shah

Shahubaid@gmail.com

Catherine Chudleigh

Catherine.Chudleigh@health.nsw.gov.au

Samantha Soe

Samantha.soe@health.nsw.gov.au

Deepak Gill

Deepak.gill@health.nsw.gov.au

Stephen Scher

sscher@mclean.harvard.edu children and adolescents referred for treatment of PNES and in 50 controls. Patients showed elevated baseline respiratory rates $[t(78)=3.34, p=.001]$, with $36 / 52(69 \%)$ of patients [vs. 11/28 (39\%) controls] falling above the 75th percentile $\left(\chi^{2}=6.7343 ; d f=1 ; p=.009\right)$. Twentyeight (47\%) of patients [vs. 4/50 (8\%) controls] showed a skewed hyperventilation-challenge profile-baseline $\mathrm{PCO}_{2}$ $<36 \mathrm{mmHg}$, a trough $\mathrm{PCO}_{2} \leq 20 \mathrm{mmHg}$, or a final $\mathrm{PCO}_{2}$ $<36 \mathrm{mmHg}$ after $15 \mathrm{~min}$ of recovery - signaling difficulties with $\mathrm{CO}_{2}$ regulation $\left(\chi^{2}=19.77 ; d f=1 ; p<.001\right)$. Children and adolescents with PNES present in a state of readiness-for-action characterized by high arousal coupled with activation of the respiratory motor system, increases in ventilation, and a hyperventilation-challenge profile shifted downward from homeostatic range. Breathing interventions that target arousal, decrease respiratory rate, and normalize ventilation and arterial $\mathrm{CO}_{2}$ may help patients shift brainbody state and avert PNES episodes.

Pascal Carrive

p.carrive@unsw.edu.au

1 Psychological Medicine, The Children's Hospital at Westmead, Locked Bag 4001, Westmead, NSW 2145, Australia

2 Brain Dynamics Centre, Westmead Institute for Medical Research, Westmead, NSW, Australia

3 University of Sydney Medical School, Sydney, NSW, Australia

4 Lady Cilento Children's Hospital, Brisbane, QLD, Australia

5 Department of Psychiatry, Harvard Medical School, Boston, MA, USA

6 McLean Hospital, Belmont, MA, USA

7 Department of Anatomy, School of Medical Sciences, University of New South Wales, Sydney, NSW 2052, Australia 
Keywords Non-epileptic seizures $\cdot$ Functional neurological symptom disorder · Conversion disorder . Dissociative convulsions $\cdot$ Hyperventilation

\section{Introduction}

Psychogenic non-epileptic seizures (PNES) is a nonspecific, umbrella category referring to non-epileptic seizures that are of presumed emotional or psychological origin, are not explained by neurological disease, and are thought to reflect abnormal central nervous system functioning [1, 2]. PNES are diagnosed following a comprehensive evaluation involving a detailed history and negative finding of ictal electrical activity on electroencephalogram [either video EEG (vEEG) or EEG telemetry] [3]. A limitation of the diagnosis is that the neurophysiological mechanisms underlying the seizures remain unexplained, whereas the current move within neurology and psychiatry is to identify the biological mechanisms that underpin different subtypes of PNES [4-7].

A growing number of studies have examined the neurophysiological characteristics of patients with PNES. Key findings include: (1) increased baseline arousal indexed by elevated cortisol, elevated heart rate (HR), decreased heart rate variability (HRV) $[8-10]^{1}$; (2) exaggerated neurophysiological responses-lower HRV recovery, increased cortisol release, and increased amplitudes of event-related potentials (ERPs) - to psychological or physiological stress stimuli [8, 14, 15]; (3) increased vigilance, and motor readiness to respond, to emotional signals $[8,11]$; (4) changes in connectivity in resting-state brain networks, with alterations in brain circuits mediating emotion regulation and arousal, cognitive control, self-referential processing, and motor planning and coordination [5]; (5) changes in EEG synchrony, both within cortical brain systems and between cortical and subcortical brain systems [16-19]; (6) arousalrelated impairments in prefrontal cortex function [12, 14]; and (7) increased avoidance tendencies to social-threat cues [20]. Taken together, these findings suggest that PNES may emerge in the context of an upregulated stress system and extreme reactivity to psychological or physiological threat stimuli.

Threat stimuli prepare the body for action by mediating increases in arousal, respiration, and motor readiness. Increases in ventilation-indexed by breathing rate and tidal volume-occur alongside a multitude of

\footnotetext{
${ }^{1}$ In the earlier studies by Kozlowska et al., children/adolescents with PNES made up 51\% $(n=29 / 57)$ of the samples [10-12]. In the most recent study of cortical arousal, children/adolescents with PNES made up $56 \%(n=32 / 57)$ of the sample [13].
}

other changes. When the breathing exceeds metabolic demands-termed hyperventilation (HV)-there is a depletion of $\mathrm{CO}_{2}$ stores, a respiratory alkalosis (high $\mathrm{pH}$ ), and biphasic brain response [see Supplemental Text Box 1 (online) for a summary of the neurophysiology of hyperventilation]. An initial excitatory phase is marked by an increase in cortical excitability in widely distributed networks [21, 22]. A subsequent hypoxic phase, mediated by cerebral artery constriction, involves a decrease in cortical function [23-25]. This hypoxic phase is marked by central symptoms, including: impaired mental performance/gaps in memory; dizziness and lightheadedness; visual phenomena (blurred, clouded, or tunnel vision; flashing lights; or complete blackout); and changes in level of consciousness ranging from disorientation/staring to a complete loss of consciousness (syncope) $[23,26,27]$. The degree of hypoxia is determined by, and proportional to, individual variations in cerebral artery constriction [28, 29]. Because the developing brain is more sensitive to the central effects of HV than the adult brain $[25,30]$, children/adolescents are likely to be more vulnerable than adults to $\mathrm{HV}$-induced changes in brain function.

In the paediatric literature, PNES secondary to HV have been described in case reports since the 1960s [31-45], but data from larger cohort studies are sparse. In two Indian studies examining the clinical characteristics of youth referred to psychological services for functional neurological symptom disorder, a quarter of the youth presenting with PNES experienced HV [6/21 (29\%) in one study; 6/25 (24\%) in the other], with or without fainting spells [40, 41]. A Hungarian study of PNES during vEEG documented HV in 14/75 (18.7\%) of child/adolescent patients [46]. In adult studies, approximately $70-83 \%$ of patients report multiple panic-like symptoms-presumably accompanied by increased respiratory rate-during PNES [47, 48]. Taken together, the above-described studies suggest that paniclike symptoms or hyperventilation occur in association with some PNES, with some indication that hyperventilation may play a causal role.

The current study used respiratory measures to assess the motor readiness of the respiratory system and the respiratory regulation of $\mathrm{CO}_{2}$ in children/adolescents referred for treatment of PNES and in controls. We hypothesized that, compared to controls, patients with PNES would show elevated baseline respiratory rates at clinical assessment and aberrant patterns of $\mathrm{PCO}_{2}$ regulation during the hyperventilation component of the vEEG, including (1) lower baseline resting $\mathrm{PCO}_{2}$ levels, (2) faster drops in $\mathrm{PCO}_{2}$, (3) lower $\mathrm{PCO}_{2}$ levels following $5 \mathrm{~min}$ of routine hyperventilation during the vEEG procedure, and (4) less efficient recoveries back to a homeostatic norm ( $\geq 36 \mathrm{mmHg}$ ) following hyperventilation. We also expected that compared to healthy 
controls, patients with PNES would show elevated baseline $\mathrm{HR}$, in line with previous findings [10].

\section{Methods}

\section{Participants}

In 2011, in a joint Neurology-Psychological Medicine project with children/adolescents being assessed for PNESThe PNES Hyperventilation Study-we added both a percutaneous probe to the vEEG to measure $\mathrm{PCO}_{2}$ and a biofeedback device (MyCalmBeat) to measure baseline respiratory rate and implement breath-control interventions [10]. In the present study we report on 60 children/adolescents, recruited from April 2011 to March 2016, who were diagnosed and treated for PNES. Four children/adolescents were excluded because $\mathrm{PCO}_{2}$ data were not collected, and four because $\mathrm{PCO}_{2}$ data were inadequate (technical difficulties or child's lack of cooperation).

Potential controls were excluded from the study if they had a past history of PNES, suffered from, or had a past history of, panic attacks or hyperventilation, or experienced an epileptic seizure during the EEG and were unable to follow instructions.

The study was approved by the Sydney Children's Hospital Network Ethics Committee. Participants and their legal guardians provided written informed consent in accordance with the National Health and Medical Research Council guidelines.

\section{Procedure}

\section{Video EEG}

Children/adolescents with PNES underwent a routine vEEG as part of their neurological assessments. Psychiatry controls underwent the same procedure as part of their inpatient medical workups, epilepsy controls as part of their epilepsy treatment, and healthy controls as volunteer participants for the study. The procedure $(35 \mathrm{~min})$ involved: an eyes-open condition (3 $\mathrm{min}$ ); an eyes-closed condition ( $2 \mathrm{~min}$ ); photic stimulation ( $3 \mathrm{~min})$; a 5-min break; and the HV challenge itself ( $5 \mathrm{~min}$ of $\mathrm{HV}$ and a 15-min recovery period). The full 10-20 electrode placement plus a single-channel electrocardiogram was used. A pulse oximeter, placed on the second finger, recorded the HR and peripheral oxygen saturation, and a percutaneous $\mathrm{PCO}_{2}$ monitor attached to the inner forearm measured the blood $\mathrm{CO}_{2}$ level throughout the procedure. The baseline resting $\mathrm{PCO}_{2}$ level was collected immediately before the commencement of $\mathrm{HV}$ (the zero value in the 20-min HV time series). High-amplitude generalized slowing on the EEG was an indicator of good physiological response to hyperventilation. The EEG scientist also used a pinwheel as a visual indicator, to encourage compliance and increase effort. All vEEG data were reviewed by a neurologist.

\section{MyCalmBeat biofeedback assessment}

All patients diagnosed with PNES attended a Psychological Medicine evaluation - a family assessment [49] and an individual assessment, where MyCalmBeat was used to document baseline respiratory rate and to assess the children/ adolescents' ability to slow down their breathing rates to upregulate vagal tone. Healthy controls completed the vEEG procedure and MyCalmBeat on the same day.

\section{Data analysis}

Table 1 lists the measures used for data analysis. A $\mathrm{PCO}_{2}$ value of $<36 \mathrm{mmHg}$ was considered to indicate hypocapnia $[50,51]$. The term skewed $H V$-challenge profile was used to describe a $\mathrm{HV}-\mathrm{PCO}_{2}$ profile that was shifted down and that was defined by baseline $\mathrm{PCO}_{2}<36 \mathrm{mmHg}$, trough $\mathrm{PCO}_{2} \leq 20 \mathrm{mmHg}$, or final $\mathrm{PCO}_{2}<36 \mathrm{mmHg}$ after $15 \mathrm{~min}$ of recovery. The $\mathrm{PCO}_{2}$ cutoff of $\leq 20 \mathrm{mmHg}$ was used for the trough- $\mathrm{PCO}_{2}$ reading that defined a skewed $\mathrm{HV}$-challenge profile because central symptoms are more likely at $\leq \mathrm{PCO}_{2}$ $20 \mathrm{mmHg}$ (range 14-29 $\mathrm{mmHg}$ ) [52]. A respiratory rate above the 75 th percentile $-\geq 19$ breaths per minute for children $8-11$ years and $\geq 21$ breaths per minute for adolescents 12-15 years-was considered to be elevated. A HR above the 75 th percentile $-\geq 100 \mathrm{bpm}$ for children $8-12$ years and $\geq 90 \mathrm{bpm}$ for children $>12$ years-was considered to be elevated. These values for respiratory rate and HR were derived from normative reference ranges [53].

A general linear model for multiple analyses was used to examine the difference in the HV-challenge curve between the PNES group and controls. Chi-square analyses and independent $t$ tests were used to calculate differences between the PNES group and the merged control group (see below) on categorical and continuous variables, respectively. For respiratory measures, all control children/adolescents were combined into one group because the three control groups showed no significant differences on any measures (see Table 2). For HR measures, the PNES group was compared only to healthy controls because baseline HR was elevated in both clinical control groups (see Table 2).

\section{Results}

\section{Clinical characteristics of participants assessed for PNES}

The clinical cohort consisted of 60 children/adolescents-42 girls and 18 boys, aged 8-17 years 
Table 1 Description of measures from the hyperventilation (HV) challenge and MyCalmBeat assessments

\begin{tabular}{|c|c|c|}
\hline Measure & Description & Units \\
\hline \multicolumn{3}{|l|}{ Baseline HR and respiratory rate } \\
\hline Clinical baseline breathing rate & The baseline breathing rate collected during the MyCalmBeat assessment & Breath per minute \\
\hline Baseline HR & $\begin{array}{l}\text { The baseline HR value from the start of the HV challenge (zero value on } \\
\text { Fig. 1) }\end{array}$ & bpm \\
\hline \multicolumn{3}{|c|}{ Hyperventilation challenge $\mathrm{PCO}_{2}$ measures } \\
\hline Baseline $\mathrm{PCO}_{2}$ & The baseline $\mathrm{PCO}_{2}$ value from the start of $\mathrm{HV}$ challenge (zero value on Fig. 1) & $\mathrm{mmHg}$ \\
\hline$\Delta \mathrm{PCO}_{2}$ & $\begin{array}{l}\text { Change in } \mathrm{PCO}_{2} \text { - the size of the } \mathrm{PCO}_{2} \text { drop-calculated as } \mathrm{HV} \text { baseline } \mathrm{PCO}_{2} \\
\text { minus lowest } \mathrm{PCO}_{2} \text { level during } \mathrm{HV} \text { challenge }\end{array}$ & $\mathrm{mmHg}$ \\
\hline Trough $\mathrm{PCO}_{2}$ & Lowest $\mathrm{PCO}_{2}$ value during $\mathrm{HV}$ challenge & $\mathrm{mmHg}$ \\
\hline Time to trough $\mathrm{PCO}_{2}$ & Time from $\mathrm{HV}$ baseline $\mathrm{PCO}_{2}$ (zero value) to trough $-\mathrm{PCO}_{2}$ value & minutes \\
\hline Rate of $\mathrm{PCO}_{2}$ drop & Rate of drop from $\mathrm{HV}$ baseline $\mathrm{PCO}_{2}$ (zero value) to trough- $\mathrm{PCO}_{2}$ value & $\mathrm{mmHg} / \mathrm{min}$ \\
\hline Rate of $\mathrm{PCO}_{2}$ recovery & $\begin{array}{l}\text { Rate of elevation of } \mathrm{PCO}_{2} \text { from trough- } \mathrm{PCO}_{2} \text { value during recovery period was } \\
\text { calculated from trough- } \mathrm{PCO}_{2} \text { value during } \mathrm{HV} \text { challenge to first value in the } \\
\text { homeostatic range }(\geq 36 \mathrm{mmHg}) \text { (if homeostasis was attained) trough- } \mathrm{PCO}_{2} \\
\text { value during } \mathrm{HV} \text { challenge to final } \mathrm{PCO}_{2} \text { value after termination of } \mathrm{HV} \text { chal- } \\
\text { lenge and } 15 \text { min of recovery (if homeostasis was not attained) }\end{array}$ & $\mathrm{mmHg} / \mathrm{min}$ \\
\hline Final $\mathrm{PCO}_{2}$ & Final $\mathrm{PCO}_{2}$ reading after termination of $\mathrm{HV}$ challenge and $15 \mathrm{~min}$ of recovery & $\mathrm{mmHg}$ \\
\hline \multicolumn{3}{|l|}{ Other terms used } \\
\hline Skewed HV profile & $\begin{array}{l}\text { A } \mathrm{HV} \text { profile that was shifted down and defined by baseline } \mathrm{PCO}_{2}<36 \mathrm{mmHg} \text {, } \\
\text { trough- } \mathrm{PCO}_{2} \leq 20 \mathrm{mmHg} \text {, or final } \mathrm{PCO}_{2}<36 \mathrm{mmHg} \text { baseline }\end{array}$ & \\
\hline
\end{tabular}

Table 2 Study measure comparisons: healthy controls vs. psychiatry controls vs. epilepsy controls

\begin{tabular}{|c|c|c|c|c|}
\hline Measure & $\begin{array}{l}\text { Mean value for psychiatry } \\
\text { controls }(n=25)\end{array}$ & $\begin{array}{l}\text { Mean value for healthy } \\
\text { controls }(n=17)\end{array}$ & $\begin{array}{l}\text { Mean value for epilepsy } \\
\text { controls }(n=8)\end{array}$ & $\begin{array}{l}t \text { ( } p \text { value) psychiatry vs. } \\
\text { healthy controls epilepsy } \\
\text { vs. healthy controls }\end{array}$ \\
\hline \multicolumn{5}{|l|}{ Baseline HR and respiratory rate } \\
\hline Baseline HR (bpm) & 87.16 & 77.24 & 86.50 & $\begin{array}{l}-2.412(0.021) \\
-1.870(0.074)\end{array}$ \\
\hline $\begin{array}{l}\text { Clinical baseline breathing rate } \\
\text { (breaths per minute) }\end{array}$ & 18.00 range $(8-24)$ & 19.71 range $(8-31)$ & Missing data & $\begin{array}{l}1.628(0.116) \\
-\end{array}$ \\
\hline \multicolumn{5}{|c|}{ Hyperventilation challenge $\mathrm{PCO}_{2}$ measures } \\
\hline Baseline $\mathrm{PCO}_{2}(\mathrm{mmHg})$ & 41.20 & 41.06 & 41.13 & $\begin{array}{l}-0.130(0.897) \\
-0.042(0.967)\end{array}$ \\
\hline$\Delta \mathrm{PCO}_{2}(\mathrm{mmHg})$ & 13.88 & 15.47 & 17.00 & $\begin{array}{l}1.397(0.170) \\
-0.944(0.355)\end{array}$ \\
\hline Trough- $\mathrm{PCO}_{2}(\mathrm{mmHg})$ & 27.32 & 25.59 & 25.00 & $\begin{array}{l}-1.435(0.159) \\
0.485(0.632)\end{array}$ \\
\hline Time to trough $\mathrm{PCO}_{2}(\mathrm{~min})$ & 5.16 & 5.53 & 4.88 & $\begin{array}{l}1.469(0.150) \\
1.674(0.108)\end{array}$ \\
\hline $\begin{array}{l}\text { Rate of } \mathrm{PCO}_{2} \text { drop }(\mathrm{mmHg} / \\
\text { min) }\end{array}$ & 2.76 & 2.89 & 2.83 & $\begin{array}{l}0.451(0.654) \\
-1.905(p=.069)\end{array}$ \\
\hline \multicolumn{5}{|l|}{ Recovery measures } \\
\hline $\begin{array}{l}\text { Rate of } \mathrm{PCO}_{2} \text { recovery }(\mathrm{mmHg} / \\
\text { min) }\end{array}$ & 4.00 & 5.56 & 3.63 & $\begin{array}{l}1.482(0.153) \\
1.302(0.206)\end{array}$ \\
\hline Final $\mathrm{PCO}_{2}(\mathrm{mmHg})$ & 41.26 & 43.65 & 44.13 & $\begin{array}{l}-1.012(0.318) \\
-1.641(0.114)\end{array}$ \\
\hline
\end{tabular}


$[$ mean $=13.45 ;$ standard deviation $(\mathrm{SD})=2.61]$-undergoing vEEG for assessment of PNES. Of the 60 patients, 7 presented with a clinical diagnosis of $\mathrm{HV}$ at referral.

The time from onset of PNES ranged from one day to 48 months (median $=2$ months). In 28 cases $(47 \%)$ the PNES presented alongside other functional neurological symptoms; in 10 cases (17\%) the PNES presented alongside chronic pain; and in 22 cases $(36.66 \%)$ the PNES were the primary presenting symptom. PNES semiology included the following: movements (rhythmic, thrashing/ kicking, flexion/extension) $(n=15)$; syncopal-like events alone $(n=11)$; visual blackout, loss of vision, or changes in consciousness associated with head dropping $(n=8)$; prolonged periods of unresponsiveness $(n=2)$; sensory experiences $(n=2)$; changes in responsiveness followed by amnesia lasting days or weeks (loss of memory of self or parents) $(n=2)$; staring episodes $(n=1)$; both movements and syncopal-like events $(n=17)$; and movements, syncopal-like events, and long periods of unresponsiveness $(n=2)$.

A third of children/adolescents (20/60;33.33\%) suffered from comorbid neurological conditions (see Table 3). All families reported antecedent stressors (range, $1-12 ;$ mean $=4.63 ;$ median $=4)$ : an illness event (accident, infection, or diagnosis or relapse of a chronic illness) (30/60; 50\%); family conflict (26/60; 43\%); maternal mental illness (typically anxiety or depression) $(26 / 60 ; 43 \%)$; being bullied $(23 / 60 ; 38 \%)$; loss due to separation $(21 / 60 ; 35 \%)$; paternal mental illness $(16 / 60$; $27 \%)$; loss due to death $(13 / 60 ; 22 \%)$; or exposure to domestic violence $(12 / 60 ; 20 \%)$. Maltreatment was less common: sexual abuse $(8 / 60 ; 13 \%)$; physical abuse $(7 / 60$; $12 \%)$; or neglect $(7 / 60 ; 12 \%)$. Comorbid motor-sensory conversion symptoms, comorbid pain, other nonspecific somatic symptoms, and comorbid psychiatric conditions diagnosed using DSM-IV-TR criteria were common and are documented in Table 3.

\section{Control group}

The control group consisted of 50 children/adolescents-27 girls and 23 boys, aged 7-17 years $($ mean $=13.63 ; \mathrm{SD}=2.50)$. Seventeen children were from control group 1 (healthy controls), 25 from control group 2 (inpatient psychiatry controls: 8 with other functional neurological symptoms; 6 with somatoform pain; and 11 with depression, self-harm, or behavioral symptoms), and 8 from control group 3 (epilepsy controls). There were no significant differences between patients and controls regarding age $[t(108)=-0.183 ; p=.855]$ and $\operatorname{sex}\left(\chi^{2}=2.99 ; p=.08\right)$.
Table 3 Comorbid neurological, medical and psychiatric diagnoses and comorbid non-specific somatic symptoms

\begin{tabular}{|c|c|c|}
\hline & $n$ & $\%$ \\
\hline \multicolumn{3}{|l|}{ Current comorbid neurological condition } \\
\hline $\begin{array}{l}\text { Epileptic seizures (one was part of a congenital } \\
\text { syndrome, see below) }\end{array}$ & 7 & 11.67 \\
\hline $\begin{array}{l}\text { Congenital condition with neurological manifesta- } \\
\text { tions (neurofibromatosis Type } 1 \text { with hydrocepha- } \\
\text { lus, epilepsy, and ocular gliomas; chromosome } \\
\text { deletion } 8 \text { with spontaneous intraventricular } \\
\text { bleeds, hydrocephalus, and ventriculo-peritoneal } \\
\text { shunting procedures) }\end{array}$ & 2 & 3.33 \\
\hline $\begin{array}{l}\text { Left cerebral atrophy of unknown cause (unchang- } \\
\text { ing over time) }\end{array}$ & 1 & 1.67 \\
\hline Cerebral palsy & 1 & 1.67 \\
\hline Hereditary angioedema & 1 & 1.67 \\
\hline Tuberous sclerosis & 1 & 1.67 \\
\hline Cerebellopontine angle cavernoma & 1 & 1.67 \\
\hline $\begin{array}{l}\text { Migraine (one child's migraines were accompanied } \\
\text { by hemiplegia) }\end{array}$ & 2 & 3.33 \\
\hline Developmental delay & 2 & 3.33 \\
\hline \multicolumn{3}{|c|}{ Past history of a neurological insult to the central nervous system } \\
\hline Past history of viral meningitis & 2 & 3.33 \\
\hline Past history of chemotherapy & 1 & 1.67 \\
\hline \multicolumn{3}{|l|}{ Other conditions or vulnerabilities } \\
\hline Type 1 diabetes & 1 & 1.67 \\
\hline Past history of Bell's palsy & 1 & 1.67 \\
\hline Hypermobility & 4 & 6.67 \\
\hline $\begin{array}{l}\text { Fainting secondary to orthostatic stress ( } 2 \text { girls, } 1 \\
\text { boy) }\end{array}$ & 3 & 5 \\
\hline Postural tachycardia syndrome (POTTS) & 5 & 8.33 \\
\hline Borderline IQ & 8 & 13.33 \\
\hline \multicolumn{3}{|l|}{$\begin{array}{l}\text { Comorbid psychological conditions and somatic } \\
\text { symptoms }\end{array}$} \\
\hline Motor-sensory conversion symptoms & 32 & 53.33 \\
\hline $\begin{array}{l}\text { Anxiety disorder (excluding PTSD and panic } \\
\text { disorder) }\end{array}$ & 22 & 36.67 \\
\hline PTSD & 7 & 11.67 \\
\hline Panic disorder & 7 & 11.67 \\
\hline Depression & 10 & 16.67 \\
\hline $\begin{array}{l}\text { Dissociative symptoms (loss of memory or capacity } \\
\text { to recognize family members) }\end{array}$ & 18 & 30 \\
\hline Behavioral disorder & 3 & 5 \\
\hline Eating disorder & 1 & 1.67 \\
\hline Comorbid pain & 41 & 68.33 \\
\hline Disturbed sleep & 23 & 38.33 \\
\hline Any nonspecific somatic symptom (excluding pain) & 53 & 88.33 \\
\hline Dizziness & 40 & 66.67 \\
\hline Breathlessness & 33 & 55 \\
\hline Nausea & 25 & 41.67 \\
\hline Fatigue & 25 & 41.67 \\
\hline Heart pounding & 20 & 33.33 \\
\hline Pins and needles & 11 & 18.33 \\
\hline
\end{tabular}




\section{Missing data}

Baseline respiratory rates recorded at the beginning of the MyCalmBeat assessment were available for $52 / 60$ children/adolescents with PNES and for 28/50 controls. HVchallenge data were available for all participants but were incomplete for 14 children/adolescents with PNES-missing the end part of the recovery period-because the procedure had been terminated early.

\section{Baseline respiratory rates at MyCalmBeat assessment}

Patients with PNES had higher baseline respiratory rates than controls [patients: mean $=24.62$; $\mathrm{SD}=8.58$; median $=24.50$; range $8-50 \mathrm{bpm}$ vs. controls: mean $=19.71 ; \mathrm{SD}=4.62$; median $=20$; range $8-31 \mathrm{bpm}(t(77.995)=3.323, p=.001)]$ (see Table 4). Using clinical reference ranges, an elevated baseline respiratory rate (above the 75th percentile) was documented in 36/52 (69\%) patients with PNES (20-50 breaths per minute; mean $=28.61 ; \mathrm{SD}=7.121 ;$ median $=26.50$ ) and 11/28 (39\%) controls (21-31 breaths per minute; mean $=23.73 ; \mathrm{SD}=2.901 ;$ median $=23.00$ ) $\left(\chi^{2}=6.7343 ; d f=1 ; p=.009\right)$.

\section{Baseline HR at hyperventilation-challenge assessment}

In line with findings from a previous study [10], patients with PNES had higher baseline HR than healthy controls (patients: mean $=90.97 ; \mathrm{SD}=12.78$; median $=91.00$; range 64-127 bpm vs. healthy controls: mean $=77.24$; $\mathrm{SD}=11.23$; median $=79.00$; range $55-97 \mathrm{bpm}[t(75)=4.008, p<.001)]$ (see Table 4). Using clinical reference ranges, an elevated baseline HR (above the 75th percentile) was documented in 29/60 (48\%) patients with PNES and 1/17 (6\%) healthy controls) $\left(\chi^{2}=10.04 ; d f=1 ; p=.002\right)$.

\section{Relationship between respiration rate and HR}

Increases in respiratory rate after the instruction to hyperventilate were followed by an increase in HR in both patients (mean change $=21 \mathrm{bpm}$ ) and controls (mean change $=23 \mathrm{bpm})[t(108)=-0.79, p=.43]$.

\section{Arterial $\mathrm{PCO}_{2}$ during the $\mathrm{HV}$ challenge of the vEEG test}

The PNES group (in red) and control group (in blue) (Fig. 1) showed clear differences in the $\mathrm{PCO}_{2}$ response to

Table 4 Between-group differences in respiratory and heart measures during the hyperventilation challenge

\begin{tabular}{|c|c|c|c|c|c|}
\hline Measure & PNES group mean value $(n=60)$ & $\begin{array}{l}\text { Control group mean value } \\
(n=50)\end{array}$ & $t$ & $p$ & Cohen's d effect size \\
\hline \multicolumn{6}{|l|}{ Baseline HR and respiratory rate } \\
\hline Baseline HR (bpm) ${ }^{\mathrm{a}}$ & 90.97 & $77.24(n=17$, healthy controls $)$ & 4.008 & $<.001$ & 0.96 \\
\hline $\begin{array}{l}\text { Clinical baseline breathing rate } \\
\text { (breaths per minute) }\end{array}$ & $\begin{array}{l}24.62(n=52 \text { due to missing } \\
\text { data) }\end{array}$ & $\begin{array}{l}19.71 \text { ( } n=28 \text { due to missing } \\
\text { data) }\end{array}$ & 3.323 & .001 & 0.64 \\
\hline \multicolumn{6}{|c|}{ Hyperventilation challenge $\mathrm{PCO}_{2}$ measures } \\
\hline Baseline $\mathrm{PCO}_{2}(\mathrm{mmHg})$ & 36.97 & 41.14 & -5.53 & $<.001$ & 1.07 \\
\hline$\Delta \mathrm{PCO}_{2}(\mathrm{mmHg})$ & 13.14 & 14.92 & -2.07 & .041 & 0.40 \\
\hline Trough- $\mathrm{PCO}_{2}(\mathrm{mmHg})$ & 23.85 & 26.36 & -3.09 & .003 & 0.59 \\
\hline Time to trough $\mathrm{PCO}_{2}(\mathrm{~min})$ & 5.13 & 5.24 & .552 & .582 & 0.11 \\
\hline Rate of $\mathrm{PCO}_{2}$ drop $(\mathrm{mmHg} / \mathrm{min})$ & 2.65 & 2.98 & -1.65 & .102 & 0.32 \\
\hline \multicolumn{6}{|l|}{ Recovery measures } \\
\hline & $n=51$ & $n=48$ & & & \\
\hline \multirow{2}{*}{$\begin{array}{l}\text { Rate of } \mathrm{PCO}_{2} \text { recovery }(\mathrm{mmHg} / \\
\text { min) }\end{array}$} & 1.94 & 3.18 & -4.09 & $<.001$ & 0.91 \\
\hline & $n=47$ & $n=50$ & & & \\
\hline Final $\mathrm{PCO}_{2}(\mathrm{mmHg})$ & 36.21 & 42.36 & -6.37 & $<.001$ & 1.40 \\
\hline Other & & & & & \\
\hline
\end{tabular}

a Analyses with HR were done between the PNES group and healthy controls because the other clinical groups also showed elevated baseline HR (see Table 3) 
the HV challenge $[F(1,94)=34.26 ; p<.001$; partial eta square $=0.267]$. The HV-challenge profile of the PNES group was shifted downward (away from homeostatic range) and characterized by a significantly lower baseline $\mathrm{PCO}_{2}$, lower trough $\mathrm{PCO}_{2}$, slower rate of $\mathrm{PCO}_{2}$ recovery, and lower final $\mathrm{PCO}_{2}$. Whereas the time to trough $\mathrm{PCO}_{2}$ and the rate of $\mathrm{PCO}_{2}$ drop were the same as in controls, the actual $\triangle \mathrm{PCO}_{2}$ with hyperventilation was smaller (see Table 4). Further analysis showed that 28/60 PNES patients (47\%) showed a skewed HV-challenge profile-defined as a baseline $\mathrm{PCO}_{2}<36 \mathrm{mmHg}$, trough $\mathrm{PCO}_{2} \leq 20 \mathrm{mmHg}$, or failure of recovery back to homeostasis-compared to only $4 / 50(8 \%)$ controls $\left(\chi^{2}=19.77 ; d f=1 ; p<.001\right)$ (see Table 5). During the HV challenge, symptoms of cerebral hypoxia-dizziness, head dropping, staring, visual changes, or changes in consciousness-were almost five times more frequent in patients with PNES (23/60) than in controls $(4 / 50)\left(\chi^{2}=13.55 ; d f=1 ; p<.001\right)$.

Observation of PNES episodes during treatment admissions showed that in 32 of the 60 patients, paroxysmal increases in ventilation-probable $\mathrm{HV}$-occurred immediately prior to PNES episodes. The $\mathrm{PCO}_{2}$ response to $\mathrm{HV}$ challenge of this "HV-induced PNES" subgroup is shown in black on Fig. 1. The average profile of this subgroup of patients was shifted even more downward (away from homeostatic range) than in the PNES group as a whole.

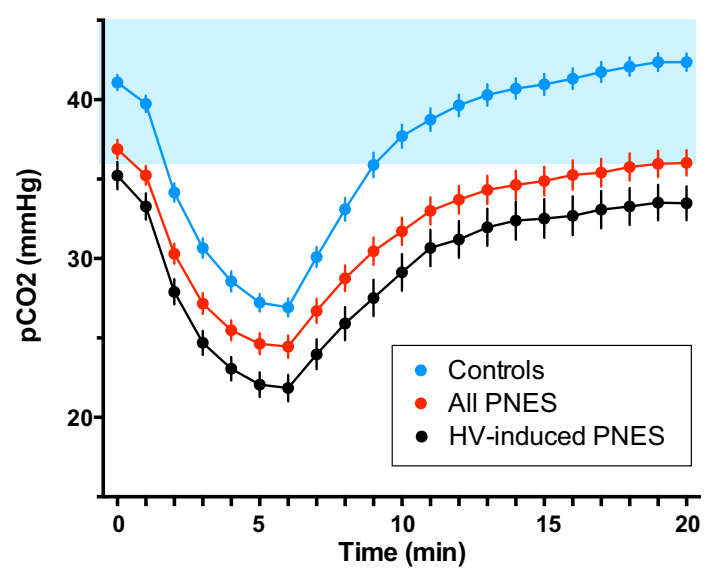

Fig. 1 Hyperventilation profiles in children and adolescents assessed for PNES and in controls. The shaded blue area depicts the homeostatic range for arterial $\mathrm{CO} 2$. The top blue line depicts controls. Controls showed a clear pattern of $\mathrm{PCO}_{2}$ changes during the $\mathrm{HV}$ task: a baseline $\mathrm{PCO}_{2}$ within the homeostatic range, a steep drop in $\mathrm{PCO}_{2}$ during $\mathrm{HV}$, and a prompt return to homeostasis during recovery. The middle red line depicts the 60 children and adolescents with PNES who participated in the study. Children and adolescents with PNES showed a downwardly skewed HV-challenge profile suggesting difficulties with $\mathrm{PCO}_{2}$ regulation. The bottom black line depicts the subgroup of 32 children and adolescents who whose PNES were typically preceded by- "triggered by"- $\mathrm{HV}$

\section{Discussion}

The PNES Hyperventilation Study used respiratory measures-baseline respiratory rate at clinical assessment and percutaneous $\mathrm{CO}_{2}$ monitoring during the hyperventilation component of routine vEEG-to assess motor readiness and $\mathrm{CO}_{2}$ regulation in children/adolescents with PNES and in controls. Baseline HR was also documented. As a group, patients with PNES had elevated baseline respiratory rates, elevated baseline HR, and skewed HV-challenge profiles, with significantly lower levels of arterial $\mathrm{CO}_{2}$ at all timepoints of the HV challenge. Symptoms of cerebral hypoxia were also almost five times more frequent in patients with PNES than in controls during the HV challenge. The study findings suggest patients presented in a state of readinessfor-action characterized by high arousal coupled with activation of the respiratory motor system and increases in ventilation. Their $\mathrm{CO}_{2}$ profiles during the $\mathrm{HV}$ challenge were shifted downward away from the homeostatic range, suggesting that excessive activation of the respiratory motor system, coupled with difficulties in regulating $\mathrm{CO}_{2}$, may contribute to the functional neural mechanisms that underpin PNES.

Although motor activity (mediated by the skeletomotor system) and sympathetic arousal (mediated by the visceromotor system) involve separate neural systems, they are interrelated and activated in a coordinated manner. Activation of the motor system (including its ventilatory component) is always coupled with sympathetic arousal, and sympathetic arousal is always coupled with activation of the motor system (at least an increase in muscle tone) [54-56]. This close interconnection between motor activation, including ventilation, and sympathetic arousal is a product of brain structure and function; the cortical areas involved in preparing and generating motor (skeletomotor) outputs overlap with those from which sympathetic (visceromotor) outputs originate [56]. Motor activity, including states of motor readiness and motor preparation, are accompanied by concurrent changes in ventilation and sympathetic output that match the metabolic demands of the movement. In the face of perceived threat, increased ventilation and a correlative increase in sympathetic arousal are part of the body's preparation for action [54, 55]. In our study, however, we found that children/adolescents with PNES had low baseline $\mathrm{PCO}_{2}$ and failure of $\mathrm{PCO}_{2}$ recovery back to homeostasis following the $\mathrm{HV}$ challenge. These findings indicate overreactivity and dysregulation of the finely tuned interconnections between motor activity and sympathetic arousal. This result matches, in part, the results of our previous studies, in which all children/adolescents with functional neurological symptoms-including the 
Table 5 Abnormal HV profiles in participants with PNES vs. controls

\begin{tabular}{|c|c|c|c|c|}
\hline Categorical variable & PNES group $n$ & Control group $n$ & Chi squared $\left(\chi^{2}\right)$ & $p$ value \\
\hline Skewed HV profile (skew in any of the three components below) & $26 / 60$ & $4 / 50$ & 19.77 & $<.001$ \\
\hline Hypocapnia at baseline $\left(\mathrm{PCO}_{2}<36 \mathrm{mmHg}\right)$ & $21 / 60$ & $3 / 50$ & 13.45 & $<.001$ \\
\hline Lowest $\mathrm{PCO}_{2} \leq 20 \mathrm{mmHg}$ & $16 / 60$ & $2 / 50$ & 10.24 & .001 \\
\hline Failure of recovery to homeostasis, or final $\mathrm{PCO}_{2}<36 \mathrm{mmHg}$ & $19 / 47$ & $1 / 50$ & 21.86 & $<.001$ \\
\hline
\end{tabular}

PNES subgroup-showed increased arousal and motor readiness to emotion stimuli. A striking difference in the PNES subgroup, however, is their excessive activation of the respiratory motor system and the associated dysregulation of $\mathrm{CO}_{2}$ control, which may well contribute to their propensity for PNES.

As noted in the introduction, neurophysiological studies show that patients with PNES demonstrate altered properties in brain networks - changes (both decreases and increases) in the relationship between cortical brain regions that normally function together $[5,16-19,57-59]$-resulting in functional disruptions in both the brain's horizontal integration (between cortical regions) and its vertical integration (between cortical and subcortical regions). These functional disruptions are likely to weaken executive control over motor areas and to prioritize reflexive control of behaviors, thereby enabling release or activation of prewired autonomous motor programs [4] - presumably those that are represented at the level of the basal ganglia, midbrain, and brainstem.

We suggest that in children/adolescents, HV may contribute to functional brain disruptions and, via two different mechanisms, to a propensity to PNES. First, because of the close coupling between respiration and sympathetic arousal, HV-induced increases in cortical arousal could trigger PNES by disrupting cortical executive control over the motor cortex and cortico-basal ganglia-thalamocortical loops. Since children/adolescents with PNES show increased baseline autonomic and cortical arousal [10, 13, 15], even minor elevations in arousal mediated by HV could disrupt cortical control and serve to disrupt cortical integration [60-62] and trigger PNES. Second, if HV continues beyond the excitatory stage into the hypoxic stage, then hypoxia-related impairments in the cortex and basal ganglia [63] will likewise contribute to dysfunction in top-down control mechanisms within the motor system and to disruptions in the brain's vertical integration. Because the basal ganglia and brain stem mediate changes in muscle tone and consciousness [64], a subset of PNES patients with HVinduced hypoxia will experience changes in consciousness and losses of muscle tone.

Contrary to our original hypothesis, we found no significant differences between patients with PNES and controls in time to lowest $\mathrm{PCO}_{2}$ levels and in rates of $\mathrm{PCO}_{2}$ drop, and the PNES group had a smaller, not greater, $\triangle \mathrm{PCO}_{2}$. These findings are consistent with a downwardly skewed $\mathrm{HV}$-challenge profile, where the $\triangle \mathrm{PCO}_{2}$ was smaller because patients had decreased reserves and reached a floor effect, as evidenced by central symptoms of $\mathrm{HV}$-induced hypoxia. Son et al. [65] likewise found that $\triangle \mathrm{PCO}_{2}$ was not useful in the assessment of EEG slowing (and of the associated cerebral dysfunction) in child/adolescent patients.

All the PNES patients in this study reported stressors prior to the onset of PNES-illness, injury, emotional distress secondary to adverse life events, or psychological trauma. Not all stressors involved psychological distress per se. These findings highlight that from the perspective of the body, the types of stressors that effect brain-body stress systems and that predispose children/adolescents to PNES go well beyond those that are subsumed under the umbrella of "psychogenic". From the perspective of the body, various stressors - pain, inflammation, and disruptions of the circadian cycle, as well as psychological stress and psychological trauma-may function to activate a sensitized, highly reactive stress system and to change functional organization of the brain [43, 60, 61, 66-70], with PNES being an unwanted by-product of the body's response to threat.

This study was carried out as part of our busy routine clinical practice. It has a number of limitations. First, although transcutaneous measures of $\mathrm{PCO}_{2}$ correlate well with arterial blood levels, the diffusion of $\mathrm{CO}_{2}$ from the blood to the skin is slow; changes in arterial $\mathrm{PCO}_{2}$ are registered with a delay of 1-2 min, and sharp changes are blunted [71]. Second, skewed HV-challenge profiles-and trough- $\mathrm{PCO}_{2}$ levels, in particular-in combination with EEG slowing are an approximate measure of $\mathrm{HV}$-induced neurophysiological changes. In future studies, more direct measures of vasoconstriction/cerebral artery blood flow (via Doppler ultrasound) would help to clarify underlying neurophysiological mechanisms, as would measuring changes in patterns of brain oxygenation (via functional magnetic resonance imaging). Third, no simple, direct measures of cortical arousal are currently available. Techniques to measure such changes on a second-to-second basis would help to clarify underlying neurophysiological mechanisms. Fourth, respiratory rates were measured at clinical assessment but not during the vEEG procedure. That said, arterial $\mathrm{CO}_{2}$ is the gold standard for measuring 
HV. Elevated respiratory rates alone (without consideration of tidal volume) can flag the possibility of HV but do not measure it directly. Finally, it would have been useful to collect data about the contribution of disturbed sleep and the menstrual cycle (in $27 / 60$ postpubertal girls) to the upregulation of the stress system [72, 73].

Despite limitations, this study contributes to current research efforts to identify the biological mechanisms that underpin PNES. The study has important implications for assessing and treating PNES in paediatric practice. Children/adolescents with PNES present in a state of increased baseline arousal. In a subset, increased arousal is coupled with excessive activation and reactivity of the motor respiratory system, and in these children/adolescents, PNES can be preceded and triggered by paroxysmal increases in arousal coupled with HV. Identifying patients in whom HV appears to trigger PNES is important because the majority of child/adolescent patients are able to utilize breathing interventions to slow their breathing, downregulate arousal, and avert PNES episodes. Once the PNES have come under control, the children, adolescents, and families are better placed to address the psychological or physiological threats that triggered their PNES in the first place.

\section{Compliance with ethical standards}

Conflict of interest The authors report no conflicts of interest. The authors alone are responsible for the content and writing of the article.

Open Access This article is distributed under the terms of the Creative Commons Attribution 4.0 International License (http://creativecommons.org/licenses/by/4.0/), which permits unrestricted use, distribution, and reproduction in any medium, provided you give appropriate credit to the original author(s) and the source, provide a link to the Creative Commons license, and indicate if changes were made.

\section{References}

1. AmericanPsychiatric A (2000) Diagnostic and statistical manual of mental disorders: DSM-IV-TR, 4th edn. American Psychiatric Association, Washington, DC

2. AmericanPsychiatric A (2013) Diagnostic and statistical manual of mental disorders: DSM-V, 4th edn. American Psychiatric Association, Washington, DC

3. Alix JJ, Kandler RH, Mordekar SR (2014) The value of long term EEG monitoring in children: a comparison of ambulatory EEG and video telemetry. Seizure J Br Epilepsy Assoc 23(8):662-665. doi:10.1016/j.seizure.2014.04.008

4. Baslet G (2011) Psychogenic non-epileptic seizures: a model of their pathogenic mechanism. Seizure J Br Epilepsy Assoc 20(1):1-13. doi:10.1016/j.seizure.2010.10.032

5. Perez DL, Dworetzky BA, Dickerson BC, Leung L, Cohn R, Baslet G, Silbersweig DA (2015) An integrative neurocircuit perspective on psychogenic nonepileptic seizures and functional movement disorders: neural functional unawareness. Clin EEG Neurosci 46(1):4-15. doi:10.1177/1550059414555905

6. Insel T, Cuthbert B, Garvey M, Heinssen R, Pine DS, Quinn K, Sanislow C, Wang P (2010) Research domain criteria (RDoC): toward a new classification framework for research on mental disorders. Am J Psychiatry 167(7):748-751. doi:10.1176/appi. ajp.2010.09091379

7. Insel TR (2013) Transforming Diagnosis. Director's Blog. http:// www.nimh.nih.gov/about/director/2013/transforming-diagnosis. shtml. Accessed Jan 2007

8. Bakvis P, Roelofs K, Kuyk J, Edelbroek PM, Swinkels WA, Spinhoven P (2009) Trauma, stress, and preconscious threat processing in patients with psychogenic nonepileptic seizures. Epilepsia 50(5):1001-1011. doi:10.1111/j.1528-1167.2008.01862.x

9. Bakvis P, Spinhoven P, Giltay EJ, Kuyk J, Edelbroek PM, Zitman FG, Roelofs K (2009) Basal hypercortisolism and trauma in patients with psychogenic nonepileptic seizures. Epilepsia 51:752-795. doi:10.1111/j.1528-1167.2009.02394.x

10. Kozlowska K, Palmer DM, Brown KJ, McLean L, Scher S, Gevirtz R, Chudleigh C, Williams LM (2015) Reduction of autonomic regulation in children and adolescents with conversion disorders. Psychosom Med 77(4):356-370. doi:10.1097/ PSY.0000000000000184

11. Kozlowska K, Brown KJ, Palmer DM, Williams LM (2013) Specific biases for identifying facial expression of emotion in children and adolescents with conversion disorders. Psychosom Med 75(3):272-280. doi:10.1097/PSY.0b013e318286be43

12. Kozlowska K, Palmer DM, Brown KJ, Scher S, Chudleigh C, Davies F, Williams LM (2015) Conversion disorder in children and adolescents: a disorder of cognitive control. J Neuropsychol 9(1):87-108. doi:10.1111/jnp.12037

13. Kozlowska K, Melkonian D, Spooner CJ, Scher S, Meares R (2016) Cortical arousal in children and adolescents with functional neurological symptoms during the auditory oddball task. Neuroimage Clin. doi:10.1016/j.nicl.2016.10.016

14. Bakvis P, Spinhoven P, Putman P, Zitman FG, Roelofs K (2010) The effect of stress induction on working memory in patients with psychogenic nonepileptic seizures. Epilepsy Behav E\&B 19(3):448-454. doi:10.1016/j.yebeh.2010.08.026

15. Kozlowska K, Melkonian D, Spooner CJ, Scher S, Meares R (2017) Cortical arousal in children and adolescents with functional neurological symptoms during the auditory oddball task. Neuroimage Clin 13:228-236. doi:10.1016/j.nicl.2016.10.016

16. Knyazeva MG, Jalili M, Frackowiak RS, Rossetti AO (2011) Psychogenic seizures and frontal disconnection: EEG synchronisation study. J Neurol Neurosurg Psychiatry 82(5):505-511. doi:10.1136/jnnp.2010.224873

17. Barzegaran E, Joudaki A, Jalili M, Rossetti AO, Frackowiak RS, Knyazeva MG (2012) Properties of functional brain networks correlate with frequency of psychogenic non-epileptic seizures. Front Hum Neurosci 6:335. doi:10.3389/fnhum.2012.00335

18. Barzegaran E, Carmeli C, Rossetti AO, Frackowiak RS, Knyazeva MG (2016) Weakened functional connectivity in patients with psychogenic non-epileptic seizures (PNES) converges on basal ganglia. J Neurol Neurosurg Psychiatry 87(3):332-337. doi:10.1136/jnnp-2014-309483

19. Umesh S, Tikka SK, Goyal N, Sinha VK, Nizamie SH (2017) Aberrant gamma band cortical sources and functional connectivity in adolescents with psychogenic non-epileptic seizures: a preliminary report. Psychiatry Res 247:51-54. doi:10.1016/j. psychres.2016.11.003

20. Bakvis P, Spinhoven P, Zitman FG, Roelofs K (2011) Automatic avoidance tendencies in patients with psychogenic nonepileptic seizures. Seizure J Br Epilepsy Assoc 20(8):628-634. doi:10.1016/j.seizure.2011.06.006 
21. Sparing R, Dafotakis M, Buelte D, Meister IG (1985) Noth J (2007) Excitability of human motor and visual cortex before, during, and after hyperventilation. J Appl Physiol 102(1):406411. doi:10.1152/japplphysiol.00770.2006

22. Carbon M, Wübbeler G, Trahms L, Curio G (2000) Hyperventilation-induced human cerebral magnetic fields noninvasively monitored by multichannel 'direct current' magnetoencephalography. Neurosci Lett 287:227-230

23. Engel GL, Ferris EB, Logan M (1947) Hyperventilation: analysis of clinical symptomatology. Ann Intern Med 27:683-704

24. Hauge A, Thoresen M, Walloe L (1980) Changes in cerebral blood flow during hyperventilation and $\mathrm{CO}_{2}^{-}$breathing measured transcutaneously in humans by a bidirectional, pulsed, ultrasound Doppler blood velocitymeter. Acta Physiol Scand 110(2):167-173

25. Yamatani M, Konishi T, Murakami M, Okuda T (1994) Hyperventilation activation on EEG recording in childhood. Epilepsia 35(6):1199-1203

26. Lum LC (1976) The syndrome of habitual chronic hyperventilation. In: Hill O (ed) Modern trends in psychosomatic medicine, vol 3. Butterworth, London, pp 196-230

27. Evans DW, Lum MB (1981) Hyperventilation as a cause of chest pain mimicking angina. Pract Cardiol 7(7):131-139

28. Gibbs DM (1992) Hyperventilation-induced cerebral ischemia in panic disorder and effect of nimodipine. Am J Psychiatry 149(11):1589-1591

29. Ball S, Shekhar A (1997) Basilar artery response to hyperventilation in panic disorder. Am J Psychiatry 154(11):1603-1604

30. Yamaguchi F, Meyer JS, Sakai F, Yamamoto M (1979) Normal human aging and cerebral vasoconstrictive responses to hypocapnia. J Neurol Sci 44(1):87-94

31. Tucker WI (1963) Hyperventilation in differential diagnosis. Med Clin N Am 47:491-497

32. Lafleur J, Reiher J (1977) Pseudoabsences. Electroencephalogr Clin 43:279-280

33. Reiher J, Lafleur J (1977) Hyperventilation induced cyclic absences. Electroencephalogr Clin 42:717

34. Wig NN, Mangalwedhe K, Bedi H, Murthy RS (1982) A follow up study of hysteria. Indian J Psychiatry 24(2):120-125

35. North KN, Ouvrier RA, Nugent M (1990) Pseudoseizures caused by hyperventilation resembling absence epilepsy. J Child Neurol 5(4):288-294

36. Bruno-Golden B, Holmes GL (1993) Hyperventilation-induced seizures in mentally impaired children. Seizure J Br Epilepsy Assoc 2(3):229-233

37. Chandra R, Srinivasan S, Chandrasekaran R, Mahadevan $S$ (1993) The prevalence of mental disorders in school-age children attending a general paediatric department in southern India. Acta Psychiatr Scand 87(3):192-196

38. Naschitz JE, Gaitini L, Mazov I, Eridzhanyan L, Keren D, Sabo E, Yeshurun D, Hardoff D, Jaffe M (1997) The capnography-tilt test for the diagnosis of hyperventilation syncope. QJM Mon J Assoc Physicians 90(2):139-145

39. Naschitz JE, Hardoff D, Bystritzki I, Yeshurun D, Gaitini L, Tamir A, Jaffe M (1998) The role of the capnography headup tilt test in the diagnosis of syncope in children and adolescents. Pediatrics 101(2):E6

40. Krishnakumar P, Sumesh P, Mathews L (2006) Temperamental traits associated with conversion disorder. Indian Pediatr 43(10):895-899

41. Deka K, Chaudhury PK, Bora K, Kalita P (2007) A study of clinical correlates and socio-demographic profile in conversion disorder. Indian J Psychiatry 49(3):205-207. doi:10.4103/0019-5545.37323

42. Barker A, Ng J, Rittey CD, Kandler RH, Mordekar SR (2012) Outcome of children with hyperventilation-induced high-amplitude rhythmic slow activity with altered awareness. Dev Med Child Neurol 54(11):1001-1005. doi:10.1111/j.1469-8749.2012.04337.x

43. Kozlowska K (2013) Stress, distress, and bodytalk: co-constructing formulations with patients who present with somatic symptoms. Harv Rev Psychiatry 21(6):314-333. doi:10.1097/ HRP.0000000000000008

44. Kozlowska K, Chudleigh C, Elliott B, Landini A (2016) The body Comes to family therapy: Treatment of a schoolaged boy with hyperventilation-induced non-epileptic seizures. Clin Child Psychol Psychiatry 21(4):669-685. doi:10.1177/1359104515621960

45. Chandra P, Kozlowska K, Cruz C, Baslet GC, Perez DL, Garralda ME (2017) Hyperventilation-induced non-epileptic seizures in an adolescent boy with pediatric medical traumatic stress. Harv Rev Psychiatry 25(4). doi:10.1097/ HRP.0000000000000131 (in press)

46. Szabo L, Siegler Z, Zubek L, Liptai Z, Korhegyi I, Bansagi B, Fogarasi A (2012) A detailed semiologic analysis of childhood psychogenic nonepileptic seizures. Epilepsia 53(3):565-570. doi:10.1111/j.1528-1167.2012.03404.x

47. Vein AM, Djukova GM, Vorobieva OV (1994) Is panic attack a mask of psychogenic seizures?-a comparative analysis of phenomenology of psychogenic seizures and panic attacks. Funct Neurol 9(3):153-159

48. Hendrickson R, Popescu A, Dixit R, Ghearing G, Bagic A (2014) Panic attack symptoms differentiate patients with epilepsy from those with psychogenic nonepileptic spells (PNES). Epilepsy Behav E\&B 37:210-214. doi:10.1016/j. yebeh.2014.06.026

49. Kozlowska K, English M, Savage B (2013) Connecting body and mind: the first interview with somatizing patients and their families. Clin Child Psychol Psychiatry 18(2):223-245

50. Fried R, Grimaldi J (1993) The psychology and physiology of breathing. Plnum Press, New York

51. Midgren B, Hansson L (1987) Changes in transcutaneous $\mathrm{PCO}_{2}$ with sleep in normal subjects and in patients with chronic respiratory diseases. Eur J Respir Dis 71(5):388-394

52. Rafferty GF, Saisch SG, Gardner WN (1992) Relation of hypocapnic symptoms to rate of fall of end-tidal $\mathrm{PCO}_{2}$ in normal subjects. Respir Med 86(4):335-340

53. Fleming S, Thompson M, Stevens R, Heneghan C, Plüddemann A, Maconochie I, Tarassenko L, Mant D (2011) Normal ranges of heart rate and respiratory rate in children from birth to 18 years of age: a systematic review of observational studies. Lancet 19(377):1011-1018. doi:10.1016/ S0140-6736(10)62226-X

54. Heistad DD, Wheeler RC, Mark AL, Schmid PG, Abboud FM (1972) Effects of adrenergic stimulation on ventilation in man. J Clin Investig 51(6):1469-1475. doi:10.1172/JCI106943

55. Chaitow L, Bradley D, Gilbert C (2002) Multidisciplinary approaches to breathing pattern disorders. Churchill Livingstone, London

56. Dum RP, Levinthal DJ, Strick PL (2016) Motor, cognitive, and affective areas of the cerebral cortex influence the adrenal medulla. Proc Natl Acad Sci USA 113(35):9922-9927. doi:10.1073/pnas.1605044113

57. Pillai JA, Haut SR, Masur D (2015) Orbitofrontal cortex dysfunction in psychogenic non-epileptic seizures. A proposal for a two-factor model. Med Hypotheses 84(4):363-369. doi:10.1016/j.mehy.2015.01.034

58. Li R, Li Y, An D, Gong Q, Zhou D, Chen H (2015) Altered regional activity and inter-regional functional connectivity in psychogenic non-epileptic seizures. Sci Rep 5:11635. doi:10.1038/srep11635 
59. Li R, Liu K, Ma X, Li Z, Duan X, An D, Gong Q, Zhou D, Chen $H$ (2015) Altered functional connectivity patterns of the insular subregions in psychogenic nonepileptic seizures. Brain Topogr 28(4):636-645. doi:10.1007/s10548-014-0413-3

60. Hermans EJ, van Marle HJ, Ossewaarde L, Henckens MJ, Qin S, van Kesteren MT, Schoots VC, Cousijn H, Rijpkema M, Oostenveld R, Fernandez G (2011) Stress-related noradrenergic activity prompts large-scale neural network reconfiguration. Science 334(6059):1151-1153. doi:10.1126/science. 1209603

61. Arnsten AF (2015) Stress weakens prefrontal networks: molecular insults to higher cognition. Nat Neurosci 18(10):1376-1385. doi:10.1038/nn.4087

62. Kitzbichler MG, Smith ML, Christensen SR, Bullmore E (2009) Broadband criticality of human brain network synchronization. PLoS Comput Biol 5(3):e1000314. doi:10.1371/journal. pcbi. 1000314

63. Gastaut H (1974) Syncopes: generalised anoxic cerebral seizures. In: Magnus O, Lorentz de Hoos AM (eds) The Epilepsies. Handbook of clinical neurology, vol 15. New Holland, Amsterdam, pp 815-835

64. Fischer DB, Boes AD, Demertzi A, Evrard HC, Laureys S, Edlow BL, Liu H, Saper CB, Pascual-Leone A, Fox MD, Geerling JC (2016) A human brain network derived from comacausing brainstem lesions. Neurology 87(23):2427-2434. doi:10.1212/WNL.0000000000003404

65. Son S, Kwon OY, Jung S, Kim YS, Kim SK, Kang H, Park KJ, Choi NC, Lim BH (2012) Relationship between hyperventilation-induced electroencephalographic changes and $\mathrm{PCO}_{2}$ level. J Epilepsy Res 2(1):5-9. doi:10.14581/jer.12002

66. Selye H (1956) The stress of life. McGraw-Hill, New York

67. Chrousos GP (2009) Stress and disorders of the stress system. Nat Rev Endocrinol 5(7):374-381. doi:10.1038/nrendo.2009.106

68. Gianaros PJ, Wager TD (2015) Brain-body pathways linking psychological stress and physical health. Curr Dir Psychol Sci 24(4):313-321. doi:10.1177/0963721415581476

69. Vachon-Presseau E, Centeno MV, Ren W, Berger SE, Tetreault P, Ghantous M, Baria A, Farmer M, Baliki MN, Schnitzer TJ, Apkarian AV (2016) The emotional brain as a predictor and amplifier of chronic pain. J Dent Res 95(6):605-612. doi:10.1177/0022034516638027

70. Shannon BJ, Dosenbach RA, Su Y, Vlassenko AG, Larson-Prior LJ, Nolan TS, Snyder AZ, Raichle ME (2013) Morning-evening variation in human brain metabolism and memory circuits. J Neurophysiol 109(5):1444-1456. doi:10.1152/jn.00651.2012

71. Hoffmann U, Essfeld D, Stegemann J (1990) Comparison of arterial, end-tidal and transcutaneous $\mathrm{PCO}_{2}$ during moderate exercise and external $\mathrm{CO}_{2}$ loading in humans. Eur J Appl Physiol $61(1-2): 1-4$

72. Vgontzas AN, Chrousos GP (2002) Sleep, the hypothalamicpituitary-adrenal axis, and cytokines: multiple interactions and disturbances in sleep disorders. Endocrinol Metab Clin North Am 31(1):15-36

73. Chrousos GP (2010) Stress and sex versus immunity and inflammation. Sci Signal 3(143):pe36. doi:10.1126/scisignal.3143pe36 